\title{
Outcomes of Single-Operator Cholangioscopy- Guided Lithotripsy in Patients with Difficult Biliary and Pancreatic Stones
}

\author{
Jorge Canena ${ }^{a, g}$, h $\quad$ Luís Lopes $^{b, e, f}$ João Fernandes ${ }^{b, c}$ Gonçalo Alexandrino ${ }^{a}$ \\ Luís Lourenço $^{a}$ Diogo Libânio ${ }^{\text {b, d }}$ David Horta ${ }^{a}$ Sílvia Giestas ${ }^{b}$ Jorge Reis ${ }^{a}$ \\ a Department of Gastroenterology, Professor Doutor Fernando Fonseca Hospital, Amadora, Portugal; \\ ${ }^{b}$ Department of Gastroenterology, Santa Luzia Hospital - Unidade Local de Saúde Alto Minho, Viana do Castelo, \\ Portugal; ' 'Gastroenterology Department, Centro Hospitalar Cova da Beira, Covilhã, Portugal; ${ }^{d}$ Department of \\ Gastroenterology, Portuguese Oncology Institute of Porto, Porto, Portugal; e Life and Health Sciences Research \\ Institute (ICVS), School of Medicine, University of Minho, Braga, Portugal; ${ }^{\prime}$ ICVS/3B's - PT Government Associate \\ Laboratory, Braga/Guimarães, Portugal; ${ }^{9}$ Cintesis - Center for Health Technology and Services Research, Porto,

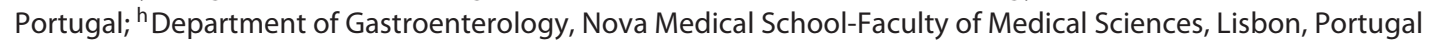

\section{Keywords}

Endoscopic retrograde cholangiopancreatography . Cholangioscopy · Laser lithotripsy · Electrohydraulic lithotripsy

\section{Abstract}

Background and Aims: Endoscopic retrograde cholangiopancreatography is the preferred strategy for the management of biliary and pancreatic duct stones. However, difficult stones occur, and electrohydraulic (EHL) and laser lithotripsy (LL) have emerged as treatment modalities for ductal clearance. Recently, single-operator cholangioscopy was introduced, permitting the routine use of these techniques. We aimed to evaluate the clinical effectiveness of cholangioscopy-guided lithotripsy using $L L$ or EHL in patients with difficult biliary or pancreatic stones. Methods: This is a prospective clinical study - conducted at two affiliated university hospitals - of 17 consecutive patients with difficult biliary and pancreatic stones who underwent single-operator cholangioscopy-guided lithotripsy using two techniques: holmi-

\section{KARGER}

E-Mail karger@karger.com www.karger.com/pjg
(C) 2018 Sociedade Portuguesa de Gastrenterologia Published by S. Karger AG, Basel

Karger

Upen access

This article is licensed under the Creative Commons AttributionNonCommercial-NoDerivatives 4.0 International License (CC BYNC-ND) (http://www.karger.com/Services/OpenAccessLicense) Usage and distribution for commercial purposes as well as any distribution of modified material requires written permission. um laser lithotripsy (HL) or bipolar EHL. We analyzed complete ductal clearance as well as the impact of the location and number of stones on clinical success and evaluated the efficacy of the two techniques used for cholangioscopyguided lithotripsy and procedural complications. Results: Twelve patients $(70.6 \%)$ had stones in the common bile duct/common hepatic duct, 2 patients (17.6\%) had a stone in the cystic stump, and 3 patients (17.6\%) had stones in the pancreas. Sixteen patients $(94.1 \%)$ were successfully managed in 1 session, and 1 patient (5.9\%) achieved ductal clearance after 3 sessions including EHL, LL, and mechanical lithotripsy. Eleven patients were successfully submitted to $\mathrm{HL}$ in 1 session using a single laser fiber. Six patients were treated with EHL: 4 patients achieved ductal clearance in 1 session with a single fiber, 1 patient obtained successful fragmentation in 1 session using two fibers, and 1 patient did not achieve ductal clearance after using two fibers and was successfully treated with a single laser fiber in a subsequent ses-

J.C. and L.L. contributed equally to this manuscript. 
sion. Complications were mild and were encountered in 6/17 patients (35.2\%), including fever $(n=3)$, pain $(n=1)$, and mild pancreatitis $(n=1)$. Conclusions: Cholangioscopy-guided lithotripsy using LL or EHL in patients with difficult biliary or pancreatic stones is highly effective with transient and minimal complications. There is a clear need to further compare $\mathrm{EHL}$ and $\mathrm{HL}$ in order to assess their role in the success of cholangioscopy-guided lithotripsy.

(C) 2018 Sociedade Portuguesa de Gastrenterologia Published by S. Karger AG, Basel

\section{Resultados da Utilização da Colangioscopia de Operador Único na Litotrícia de Cálculos Difíceis Biliares e Pancreáticos}

\section{Palavras Chave}

CPRE · Colangioscopia · Litotrícia por laser · Litotrícia eletrohidráulica

\section{Resumo}

Introdução: A CPRE é o exame preferencial para a remoção de cálculos biliares e pancreáticos. Em situações de cálculos difíceis foram propostas novas modalidades terapêuticas como a litotrícia electro-hidráulica (LEH) e a litotrícia por laser (LL). Recentemente a disponibilidade da colongioscopia de operador-único tornaram estas técnicas mais acessíveis e fáceis de realizar. Procuramos avaliar a eficácia clínica de litotrícia guiada por colangioscopia recorrendo à LEH ou à LL em doentes com cálculos biliares e pancreáticos difíceis. Métodos: Estudo prospetivo, conduzido em 2 Hospitais associados à Universidade e englobando 17 doentes consecutivos com cálculos difíceis biliares e pancreáticos, estes doentes foram tratados com litotrícia guiada por colangioscopia recorrendo a LEH ou LL. Analisamos a limpeza completa dos ductos, bem como o impato do número de pedras e localização no sucesso clínico, associada à avaliação das 2 técnicas de litotrícia e complicações desta abordagem terapêutica. Resultados: Doze doentes (70.6\%) tinham cálculos no colédoco/hepático comum, 2 doentes (17.6\%) tinham um cálculo único no coto do cístico e 3 doentes (17.6\%) apresentavam cálculos pancreáticos. Dezasseis (94.1\%) doentes foram tratados com sucesso numa única sessão e o restante (5.9\%) doente necessitou de 3 sessões incluído LEH, LL e litotrícia mecânica para obter limpeza dos ductos. Onze doentes foram tratados com LL e obtiveram sucesso clínico numa única sessão com uma fibra única de laser. Seis doentes foram tratados com LEH: 4 doentes obtiveram sucesso clínico numa única sessão com 1 fibra; 1 doente necessitou de 2 fibras para obter limpeza ductal numa sessão única. O último doente falhou a limpeza dos ductos com duas fibras de LEH e necessitou de sessão adicional com Laser (uma fibra) para obter fragmentação adequada dos cálculos. As complicações foram ligeiras em 6/17 (35.2\%) doentes e incluíram febre $(n=4)$, dor $(n=1)$ e pancreatite ligeira $(n=1)$. Conclusões: A litotrícia guiada por colangioscopia com recurso a LEH ou LL em doentes com cálculos difíceis biliares e pancreáticos é muito eficaz e está associada a complicações transitórias e ligeiras. Existe clara necessidade de realizar estudos comparativos entre LEH e LL.

(C) 2018 Sociedade Portuguesa de Gastrenterologia Publicado por S. Karger AG, Basel

\section{Introduction}

Endoscopic retrograde cholangiopancreatography (ERCP) has emerged as the standard treatment for the management of biliary and pancreatic stone disease [13]. Extraction of bile or pancreatic duct stones can be achieved with conventional techniques such as extraction baskets, balloons, or mechanical lithotripsy, with success rates up to 95\% [2-4]. However, biliary and pancreatic stones that cannot be removed by conventional techniques occur, and these difficult stones include very large stones, impacted stones, and stones in difficult locations, namely, cystic or intrahepatic stones and pancreatic stones that are large or proximal to a stricture. These difficult-to-remove stones need multiple procedures, extracorporeal shock wave lithotripsy, and even more invasive methods for complete ductal clearance [2-5].

ERCP-guided electrohydraulic (EHL) and laser lithotripsy (LL) were first introduced in the 1980s for difficult stones, and they were found to be effective in these clinically challenging cases $[6,7]$. Holmium LL (HL) was first reported in 1998 [8]. However, all these techniques produce high energy levels and require clear vision of the duct - that is, a cholangioscopy-guided approach - to avoid serious injury to the biliary/pancreatic ducts. Classic cholangioscopes using the "mother-baby" technique are limited by their fragility, complex setup, and moderate visual resolution and the need for two experienced operators to work together. Recently, a single-operator cholangioscopy system has been introduced, which allows a more routine use of these technologies $[9,10]$. This device has been improved, and the second-generation 
digital system permits superior visualization of the biliary and pancreatic system when compared with the original device [4].

Recent reports have suggested that cholangioscopyguided LL is a safe and effective technique for the treatment of difficult biliary and pancreatic stones, although the experience with pancreatic stones is more limited [2$5,11,12]$. There is no reported experience in Portugal with the second-generation digital cholangioscopy-guided lithotripsy system using EHL or HL. Therefore, we conducted a prospective study aiming to evaluate the efficacy and safety of cholangioscopy-guided lithotripsy using LL or EHL in patients with difficult biliary or pancreatic stones.

\section{Subjects and Methods}

\section{Patients and Setting}

This is a prospective clinical study with a single-arm design conducted at two affiliated university hospitals (Professor Doutor Fernando Fonseca Hospital and Santa Luzia Hospital). Between January and December 2017, all of the consecutive patients with difficult biliary and pancreatic stones who were managed with single-operator cholangioscopy-guided lithotripsy were included in the study.

The following criteria were used for inclusion in this study: (1) having 1 or more biliary stones that failed treatment by mechanical lithotripsy and/or balloon sphincteroplasty; (2) having impacted stones or stones in difficult locations (cystic stump or intrahepatic ducts); and (3) having symptomatic chronic calcific pancreatitis (pain with analgesic dependence and previous attacks of pancreatitis) with pancreatic stones that were not amenable to being removed by a stone retrieval basket or balloon and/or having obstructing stones (proximal to a stricture) in the pancreatic head or body. Patients with distorted anatomy, malignant strictures, and bleeding diatheses were excluded from the study.

\section{Endpoints and Definitions}

The primary endpoint was clinical success defined as complete ductal clearance determined by cholangioscopy or pancreatoscopy associated with an occlusion cholangiogram or pancreatogram. Secondary endpoints included the assessment of safety, the impact of the location and number of stones on clinical success, and an evaluation of the efficacy of the two techniques used for cholangioscopy-guided lithotripsy, namely, holmium laser technology or the bipolar EHL system. Stone impaction was defined as an immobile stone that precluded guidewire and/or basket/mechanical lithotripter passage. Complications were defined as any adverse events related to cholangioscopy-guided lithotripsy, and they were carefully monitored using previously specified definitions [13].

\section{Endoscopic Technique and Lithotripsy}

The ERCP procedures were performed with the patients in the prone position under sedation with propofol administration by an anesthesiologist. All patients received an intraprocedural dose of intravenous antibiotics (third-generation cephalosporin or fluoro-
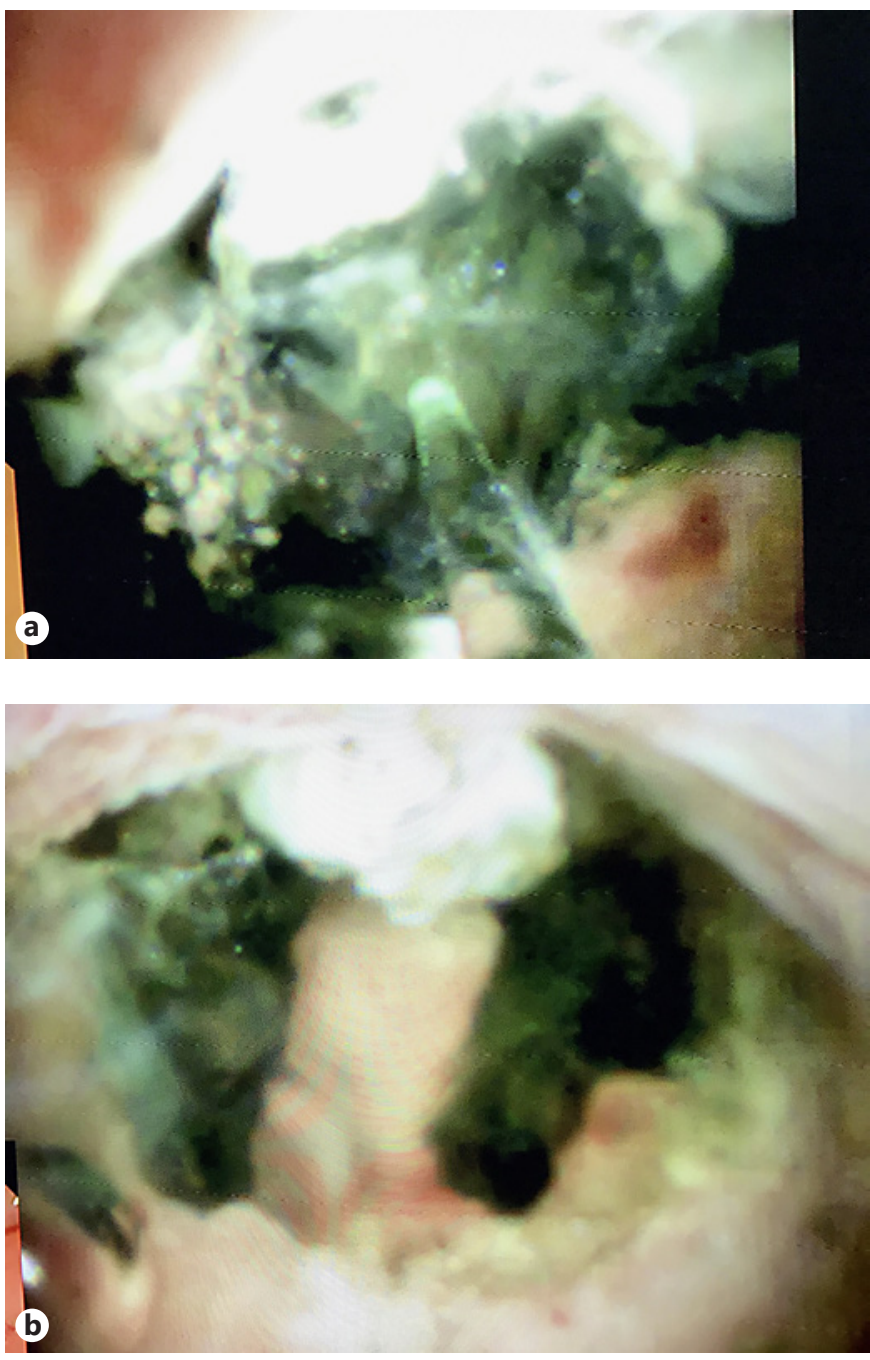

Fig. 1. Cholangioscopy-guided laser lithotripsy of a large bile duct stone. a Laser fiber and green aiming beam targeting the stone. b Successful fragmentation of the stone after laser bursts.

quinolone). The techniques of cholangioscopy, pancreatoscopy, and lithotripsy have been described in previous publications. Briefly, all patients had previously been submitted to biliary or pancreatic sphincterotomy; however, when deemed necessary, an extension of the existing sphincterotomy or balloon sphincteroplasty was performed to facilitate the easy passage of the visualization system. Cholangioscopy/pancreatoscopy was performed with the second-generation SpyGlass Direct Visualization System (SGDS), using a single-operator four-way deflected 10-Fr SpyScope (Boston Scientific, Natick, MA, USA) inserted through the $4.2-\mathrm{mm}$ working channel of a therapeutic duodenoscope. In ductal lithotripsy, we used two different techniques for the SpyScopeguided lithotripsy: holmium laser technology and the bipolar EHL system.

Holmium Laser Technology. We used this technology (Auriga XL 50W, model 4007; Boston Scientific) with a dedicated 365- $\mu \mathrm{m}$ diameter fiber (LightTrail Fiber; Boston Scientific), with energy 
Table 1. Demographic and baseline patient data $(n=17)$

\begin{tabular}{lc}
\hline Median age (range), years & $72(42-90)$ \\
Sex, $n(\%)$ & $11(65)$ \\
$\quad$ Male & $6(35)$ \\
Female & $9(52.9)$ \\
Previous cholecystectomy, $n(\%)$ & \\
Prior ERCPs procedures & $2(1-7)$ \\
Median number of procedures (range) & 5 \\
1 procedure & 5 \\
2 procedures & 7 \\
$>3$ procedures & \\
\hline
\end{tabular}

Table 2. Indications, stone locations, and characteristics $(n=17)$

\begin{tabular}{lr}
\hline Indication, $n$ (\%) & $14(82.4)$ \\
Biliary stones & $3(17.6)$ \\
Pancreatic stones & \\
\hline Stone location, $n$ (\%) & $14(82.4)$ \\
Biliary tree & $12(70.6)$ \\
$\quad$ Common bile duct/common hepatic duct & $2(11.8)$ \\
$\quad$ Cystic stump & $3(17.6)$ \\
Pancreatic duct & $2(11.8)$ \\
$\quad$ Body & $1(5.9)$ \\
$\quad$ Head & $1(5.9)$ \\
\hline Impacted stone, $n$ (\%) & \\
\hline Stone characteristics & $17(10-40)$ \\
Biliary & \\
$\quad$ Median stone size (range), mm & $2(1-4)$ \\
$\quad$ Number of stones & 7 \\
$\quad$ Median number of stones (range) & 2 \\
$\quad 1$ stone & 5 \\
$\quad>3$ stones & \\
Pancreatic & $6(5-7)$ \\
Median stone size (range), mm & $2(1-3)$ \\
Median number of stones (range) & \\
\hline
\end{tabular}

levels set at $800-1,500 \mathrm{~mJ}$ and a frequency of 8-15 Hz. For biliary stones, most of the times, we used a frequency of $12 \mathrm{~Hz}$ and an energy level of 1,200-1,500 mJ. For pancreatic stones, we used a frequency of $8-10 \mathrm{~Hz}$ and an energy level of $800-1,200 \mathrm{~mJ}$. The tip of the laser fiber has a green aiming beam (brightening regulated), which was used to target the stone under direct vision. With the probe tip 1-2 mm away from the stone, and under continuous or intermittent saline irrigation, laser bursts were delivered through the aqueous medium until stone fragmentation was deemed complete (Fig. 1).

Bipolar EHL System. We used this system (Autolith Touch Biliary EHL System; Boston Scientific) with a dedicated 1.9-Fr 375$\mathrm{cm}$ EHL probe (Boston Scientific) which was optimized for use with the SGDS. The probe was used with the following parameters: low, medium, or high power depending on the technical challenge, and $5-10$ pulses per foot pedal activation. The probe is used only in aqueous medium under continuous or intermittent saline irrigation. The probe has no aiming beam and is used with the probe tip touching or 1-2 $\mathrm{mm}$ away from the stone.

The choice of the cholangioscopy-guided lithotripsy system depended on system availability and on the preferences of the endoscopist. When performing cholangioscopy, the SpyScope was inserted through the papilla and advanced to the common bile duct or cystic stump towards the stone of interest, with endoscopic vision and intermittent fluoroscopy. When deemed necessary, the cholangioscope was advanced over a stiff 0.025 -inch guidewire. After direct visualization of the stone, the guidewire was changed by the 1.9-Fr EHL probe. When using the holmium laser technology, the fiber was preloaded into the cholangioscope's $1.2-\mathrm{mm}$ working channel, which allows the simultaneous presence of the laser fiber and the 0.025-inch guidewire. For pancreatoscopy, the SpyScope was always advanced over the 0.025 -inch guidewire. The energy of the laser fiber or of the EHL probe was delivered until stone fragmentation was deemed complete. Fragmented stones were removed with conventional extraction devices at the discretion of the endoscopist, which may have included mechanical lithotripsy. In case complete ductal clearance was not achieved in 1 session, 1 or more plastic biliary or pancreatic stents were inserted until the next session.

\section{Follow-Up and Statistical Analysis}

The patients were followed up for at least 1 month, with subsequent visits and blood analysis. Categorical data are shown as absolute and relative frequencies, and quantitative data are summarized as mean and standard deviation or as median and range according to the normality of the distribution. All statistical analyses were performed using the Stata software package version 14 (StataCorp 2015, Stata Statistical Software, Release 14; StataCorp, College Station, TX, USA).

\section{Results}

In total, 17 patients ( 6 women and 11 men) with a median age of 72 years (range 42-90) were enrolled in the study. The patient demographics and prior interventions are summarized in Table 1 . All of the patients had failed at least 1 prior stone removal attempt (median 2; range $1-7)$ using conventional stone extraction techniques. Of the 17 patients included in the study, 12 patients (70.6\%) had stones in the common bile duct/common hepatic duct (median number of stones 2.5; range 1-4) (Table 2). Of these 12 patients, 1 patient had an impacted stone in the mid common bile duct and 2 patients had intrahepatic stones associated with stones in the common bile duct/common hepatic duct. Three patients (17.6\%) had stones in the pancreas (median number of stones 2; range $1-3)$ and 2 patients (11.8\%) had a single stone in the cystic stump. In total, the median procedural time of cholangioscopy-guided lithotripsy was 55 min (range 30-100) (Table 3). 
Table 3. Cholangioscopy-guided lithotripsy duration, technique, and main outcomes $(n=17)$

\begin{tabular}{lc}
\hline Median duration (range), min & $55(30-100)$ \\
\hline Lithotripsy technique, $n(\%)$ & $11(64.7)$ \\
Holmium laser & $6(35.3)$ \\
EHL & $1(5.9)$ \\
EHL + holmium laser & \\
\hline Successful stone clearance, $n(\%)$ & $17(100)$ \\
Overall & $16(94.1)$ \\
$\quad$ In 1 session & $1(5.9)$ \\
$\quad$ In 3 sessions ${ }^{1}$ & \\
\hline Adverse events, $n$ (\%) & $6(35.3)$ \\
Overall & $4(23.5)$ \\
$\quad$ Fever & $1(5.9)$ \\
Pancreatitis (mild) & $1(5.9)$ \\
\hline
\end{tabular}

EHL, electrohydraulic lithotripsy. ${ }^{1}$ The patient was submitted to holmium laser, EHL, and mechanical lithotripsy. The final ductal clearance was obtained by an occlusion cholangiogram only.

\section{Primary Endpoint}

Complete ductal clearance was achieved in 17/17 patients (100\%) after a median number of 1 session (range $1-3)$. In total, $16 / 17$ patients (94.1\%) achieved complete removal of their stones in 1 session, and in the remaining patient $(1 / 17 ; 5.9 \%)$, ductal clearance was obtained after 3 sessions.

\section{Biliary Endotherapy}

Of the 14 patients with difficult biliary stones, 12 patients (85.7\%) had stones in the common bile duct/common hepatic duct and 2 patients (14.3\%) had a single stone in the cystic stump (median diameter $10.5 \mathrm{~mm}$; range 11-12) (Fig. 2). In total, the 14 patients had a median number of 2 biliary stones (range 1-4) with a median diameter of $17 \mathrm{~mm}$ (range 10-40). Of the 14 patients, 2 patients with stones in the common bile duct/common hepatic duct had an associated stone in the right hepatic duct (7 and $8 \mathrm{~mm}$, respectively), which was also successfully submitted to cholangioscopy-guided lithotripsy.

Of the 14 patients, 1 patient with 2 stones of 20 and 40 mm was submitted to 3 sessions: in the first session, the patient was submitted to endotherapy with an EHL probe; after using two probes, none of the 2 stones was considered to be adequately fragmented, and the procedure was stopped and 2 biliary stents were left in the bile duct. In the second session, the patient was submitted to cholangioscopy-guided lithotripsy with holmium laser technol-
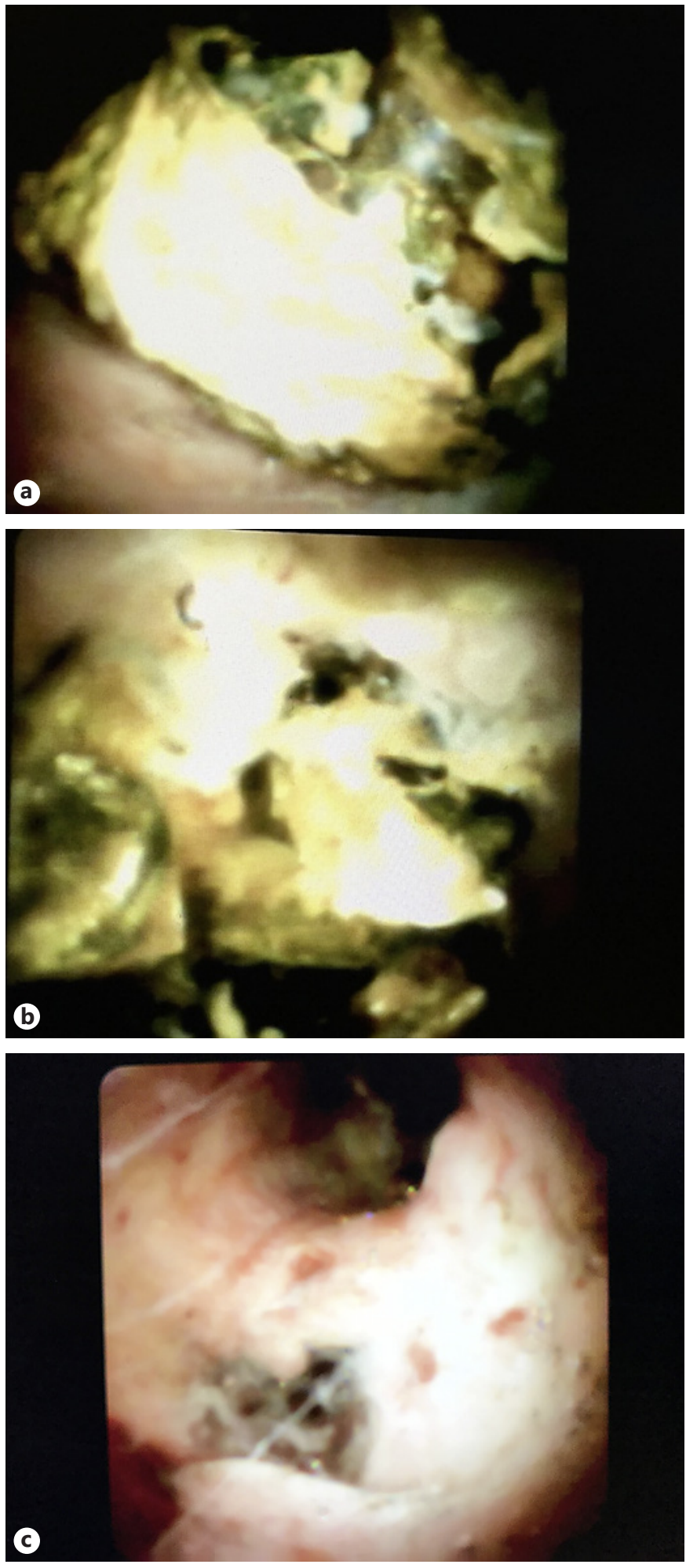

Fig. 2. Mirizzi syndrome associated with a large stone remaining in the cystic stump. a Image of a large impacted stone in the cystic stump. b Fragmentation of the stone using electrohydraulic lithotripsy. c Final image showing clearance of the bifurcation of the cystic stump/common bile duct. 
ogy with successful fragmentation of the stones and partial clearance of the ductal fragments (online suppl. Video S1; see www.karger.com/doi/10.1159/000488508 for all online suppl. Material). Between the second and the third session, 2 biliary stents were left in place, and in the third session the patient was submitted to treatment with conventional extraction devices including mechanical lithotripsy and achieved ductal clearance, which was only determined by an occlusion cholangiogram. This patient, with 90 years of age and a considerable number of comorbidities, had previously been submitted to several ERCPs with stent exchanges due to failed attempts at stone extraction.

\section{Pancreatic Endotherapy}

Of the 3 patients ( 3 men) who were submitted to ductal lithotripsy, all had impacted stones in the head or body precluding conventional extraction and further stenting of the pancreas. All the patients had symptomatic disease with analgesic dependence and previous attacks of pancreatitis. None of the patients had been previously submitted to extracorporeal shock wave lithotripsy. The 3 patients had a median number of 2 pancreatic stones (range 1-3) with a median diameter of $6 \mathrm{~mm}$ (range 5-7). All of the pancreatic stone patients were successfully submitted to cholangioscopy-guided lithotripsy in a single session, 2 patients using the EHL probe and 1 patient using the holmium laser technology.

One patient had an impacted stone of $6 \mathrm{~mm}$ in the mid pancreatic body and associated dilatation in the tail and proximal body. The patient was submitted to cholangioscopy-guided lithotripsy with the holmium laser technology. After successful treatment of the stone in 1 session, the stricture was further submitted to an increased number of plastic stents, and at the end of endotherapy the patient remained asymptomatic during follow-up (6 months) without further interventions. One patient had 3 stones impacting the distal pancreatic body (median diameter $6 \mathrm{~mm}$; range 5-7) that had failed basket or balloon clearance and at the same time precluded the treatment of the associated stricture. The patient was treated with the EHL probe in a single session (using 1 probe) allowing ductal clearance and sequential stricture stenting and treatment. The third patient had 2 stones in the head (median diameter $6 \mathrm{~mm}$; range 5-7) impacting a stricture located at the transition between the genu and the head. They were successfully fragmented with the EHL probe (1 probe) in a single session. The patient was successfully submitted to further stricture stenting and remained asymptomatic after 3 months. In total, the median proce- dural time of cholangioscopy-guided lithotripsy for pancreatic endotherapy was 50 min (range 45-60).

\section{Efficacy of the EHL Probe and HL}

In total, 6 patients were submitted to cholangioscopyguided EHL and 11 patients were submitted to HL. Of the 6 patients treated by EHL, 2 patients had stones in the main pancreatic duct, 1 patient had a stone in the cystic stump, 1 patient had 3 stones in the common bile duct/ common hepatic duct (median size $15 \mathrm{~mm}$; range 12-25), 1 patient had 4 stones in the common bile duct/common hepatic duct (median size $17 \mathrm{~mm}$; range 15-20), and 1 patient had 2 stones in the common hepatic duct (median size $30 \mathrm{~mm}$; range $20-40$ ). The first 4 patients were treated in a single session using a single probe. The patient with 4 stones in the common bile duct/common hepatic duct was treated in a single session using 2 probes. The sixth patient failed the first session using 2 EHL probes (see above in the Biliary Endotherapy section). He crossed to endotherapy with HL and obtained ductal clearance in 2 additional sessions.

In total, 11 patients were treated with a dedicated laser fiber. One patient had a stone of $10 \mathrm{~mm}$ in the cystic stump. One patient had a 6-mm stone in the pancreas, and 9 patients had a medium number of 2 stones (range: $1-4)$ in the common bile duct/common hepatic duct with a median diameter of $19 \mathrm{~mm}$ (12-25). All of the patients submitted to HL achieved ductal clearance in 1 session with a single dedicated laser fiber.

\section{Complications}

Complications were encountered in 6 of the 17 patients (35.3\%). Four patients had transient fever between 37.9 and $39.2^{\circ} \mathrm{C}$ during $24 \mathrm{~h}$ ( 3 patients) and $48 \mathrm{~h}$ (1 patient). The fever was managed conservatively, with fever clearance after $48 \mathrm{~h}$. One patient (submitted to pancreatic endotherapy) experienced pain during the first $6 \mathrm{~h}$ after endotherapy and 1 patient had a mild post-ERCP pancreatitis. The 2 patients responded well to conservative management and were discharged within 3 days.

\section{Discussion}

The present study was designed to assess the clinical effectiveness and safety of SGDS-guided HL and EHL in the management of patients with difficult-to-remove bile duct and pancreatic stones. In our work, these advanced lithotripsy techniques were highly effective, demonstrating a $94.1 \%$ overall stone clearance rate ( $16 / 17$ patients) 
in a single session, and a good safety profile. All patients except one required just a single session to completely remove the stones. In the only patient that had incomplete stone clearance in the first session (using EHL), the stones were removed after 2 additional sessions, using LL in the second session to further stone fragmentation and including mechanical lithotripsy to accelerate ductal clearance in the third session. Procedure-related adverse events, albeit mild, occurred in 6 patients ( 1 patient had mild pancreatitis and 4 patients had transitory fever), but in all cases they resolved uneventfully with conservative measures.

The majority of our patients had difficult biliary stones previously submitted to multiple ERCPs (median 2), with unsuccessful bile duct stone removal despite mechanical lithotripsy and/or balloon dilation. In our study, complete stone clearance was accomplished in a single session in $94.1 \%(16 / 17)$ of the patients. The remaining patient in our series achieved stone clearance after 2 incomplete sessions of cholangioscopy guided-lithotripsy and a third session with conventional extraction devices including mechanical lithotripsy. This patient had 2 difficult biliary stones, one $20 \mathrm{~mm}$ and the other $40 \mathrm{~mm}$ in size, impacted in the common hepatic duct and was referred to our center because of previously failed attempts of stone removal. Although, ultimately, cholangioscopy was not done in the last session, the occlusion cholangiogram demonstrated successful ductal clearance. Therefore, not being a success according to the protocol, final ductal clearance was only possible by cholangioscopy guided-lithotripsy.

Several other studies have demonstrated successful management of difficult biliary stones using cholangioscopy-guided LL and EHL, with success rates ranging from 67 to $100 \%$ [2-5, 12]. In a large series that enrolled 69 patients with complex biliary stones treated with SGDS-guided HL, Patel et al. [3] reported a successful extraction rate of $74 \%$ in the index ERCP. This value increased to $97 \%$ after additional sessions. Wong et al. [4] - in a more recent prospective cohort study involving 17 patients with complex biliary stones, preferentially using HL laser - reported a success rate of $63 \%$ in the first ERCP. After additional sessions, the overall success rate increased to $75 \%$. Our higher success rate in the first ERCP session than in prior reports is comparable to the success rate reported in more recent publications, such as in a large series of 36 patients by Navaneethan et al. [14] enrolled in a multicenter study. They reported an initial success rate of bile duct stone removal of $87.1 \%$, which increased to $100 \%$ after additional sessions. In the future, this high success rate will probably lead to the progressive

Cholangioscopy-Guided Lithotripsy adoption of these techniques for complex biliary stones. This apparent trend toward higher success rates in more recent reports $[4,12,14]$ is likely to be related to cumulative experience with the technique combined with the introduction of the second generation of the SGDS system in 2012.

The SpyGlass is a single-operator cholangioscope which overcomes some of the limitations of other cholangioscopes available in the market. The mother-daughter peroral cholangioscopes were fragile, expensive (due to frequent repairs), and sometimes difficult to insert in the bile duct, required two experienced endoscopists, and had only two-way tip deflection. This new system, with improved image quality and four-way steering of the tip, has a separated irrigation and suction channel through an outside port. One of its major advantages is the easiness of its insertion into the common bile duct through the papilla from the duodenoscope, as well as its resistance. Despite the fair quality of endoscopic view provided, there is considerable room for improvement, especially when we compare it with the quality of the new digital endoscopes used in clinical routine.

We used both HL and EHL on our patients with biliary stones, according to the preferences of the endoscopist and the equipment available. The holmium laser is the newest laser lithotripter introduced for stone fragmentation, with excellent results and limited collateral effects $[7,14,15]$. On 11 patients, we used HL in the index ERCP and the stones were completely removed in 1 session using only 1 probe. The remaining patients, for which EHL was the first choice, failed ductal clearance after using 2 probes, and therefore HL was used in a subsequent session; the stones were adequately fragmented after that session with a single laser probe. Another patient underwent EHL with 4 large stones, needing 2 EHL probes in a single session to achieve ductal clearance.

EHL probes have a limited life span, which is proportional to the potency chosen during the procedure. In contrast, HL probes do not have this limitation, but they are more expensive (with a difference between EUR 100 and 200 depending on the country and the technology used). Probably we should opt for laser probes for very large or multiple stones to overcome this limitation of EHL probes. A recent multicenter study has addressed this issue assessing 406 patients [12]. This retrospective study compared outcomes between 306 patients submitted to EHL and 101 patients treated with HL. The authors concluded that the final rate of ductal clearance was similar using the two techniques (96.7 and 99\% with EHL and HL, respectively). However, there was a trend favoring 
HL with regard to efficacy in a single initial session (86.1 vs. $74.5 \%$ ) and a statistically significant difference in median duration of the procedure in favor of HL (49.9 vs. $73.9 \mathrm{~min} ; p<0.001)$. However, this study did not explore the number of probes used and recommendations for choosing EHL or HL; therefore, more studies are warranted that compare the two lithotripsy techniques, including cost-effectiveness analyses.

Notwithstanding, given the heterogeneity in the studies published and the limited number of patients included - with different inclusion criteria, lithotripsy techniques used (i.e., different lasers), and even outcome definitions - it is difficult to draw definite conclusions. Most of the studies are retrospective, and some use prospective cohorts. There is a scarcity of randomized controlled trials [15].

Despite the small number of patients, we demonstrated a $100 \%$ success rate in ductal clearance of pancreatic stones in 3 patients with chronic pancreatitis. Our results are comparable with those of other reports (there are only few reports published), most of them based on a small number of patients $[2,5]$. In a retrospective study including 5 patients with chronic pancreatitis and stones located in the body and neck, HL was successful in the first session for all patients [2]. In the largest published series, Attwell et al. [5] analyzed 28 patients with chronic calcific pancreatitis previously submitted to extracorporeal shock wave lithotripsy. This paper reports complete ductal clearance in $79 \%$ of the patients and partial clearance in $11 \%$ of the cases. The authors concluded that this technique is feasible and is associated with clinical improvement in selected patients [5]. In our study, we were successful in 3 out of 3 cases (100\%), with stones located more distally - in 2 patients in the body - which increased the grade of difficulty of the procedure. This technique could replace extracorporeal shock wave lithotripsy as the first-line treatment or be used as a complement to extracorporeal shock wave lithotripsy for difficult pancreatic stones in the main pancreatic duct [5].

A study by Sethi et al. [16] suggests that ERCP with cholangioscopy may be associated with higher total rates of adverse events, especially cholangitis despite antibiotic prophylaxis. The authors proposed that this risk could be explained by the increased biliary pressure during the procedure secondary to the frequent irrigation of the biliary tree with water. In our study, we had 6 patients with adverse events, all mild (35.3\%). The most common was fever for less than $48 \mathrm{~h}$. All patients had received $200 \mathrm{mg}$ of ciprofloxacin before the procedure. The overall complication rates reported in the literature are diverse, rang- ing from 4.1 to $21.4 \%$. The definitions of complications and study designs used are heterogeneous, which limits their comparability. However, given the high number of patients with fever, we closely monitor this adverse event, and perhaps, in the future, antibiotics should be continued some days after the procedure.

Despite the high efficacy of these advanced lithotripsy techniques, we should be aware that some patients will need multiple sessions in order to limit the length of each ERCP session for safety reasons. We should bear in mind that a large majority of patients, especially with difficult biliary stones, are elderly and have an advanced ASA grade. In our cohort, the oldest patient was 90 years of age, and half of the patients were over 72 years old.

Further studies are needed on this topic: (a) studies comparing the efficacy and costs of EHL and HL; (b) studies assessing the cost-effectiveness of these techniques, in particular evaluating whether an earlier introduction of these technologies is not justified, thereby avoiding the implementation of several ERCPs (with stent exchange and failed attempts at stone removal) and the morbidity and costs associated with these procedures; and (c) studies evaluating the efficacy of cholangioscopyguided lithotripsy in a specific group of patients with intrahepatic lithiasis.

This study has several limitations, including the limited number of patients and the lack of a control group. It was carried out in two high-volume centers by two endoscopists experienced in complex endoscopic endotherapy (J.C. and L.L.). Thus, the results cannot be generalized to other centers with less experience in advanced pancreatobiliary endoscopy. Given the limited number of patients with difficult stones available, we should implement a national registry for this advanced technique. Notwithstanding, our study has some strengths that should be mentioned. First, its prospective design should be mentioned, with the support from a registry database and the collection of data by an independent researcher. To our knowledge, including 17 patients this is the largest prospective cohort study performed in Portugal evaluating the outcomes and safety of SpyGlass-guided lithotripsy.

In conclusion, cholangioscopy-guided lithotripsy using LL or EHL in patients with difficult biliary or pancreatic stones is highly effective with transient and minimal complications. There is a clear need to further compare EHL and laser technology to assess their role in the success of cholangioscopy-guided lithotripsy. 


\section{Statement of Ethics}

All patients provided written informed consent before initiation of the procedures. Each of the institutional review boards involved in this study approved this research.

\section{Disclosure Statement}

Jorge Canena is a consultant for Boston Scientific but did not receive any financial arrangements for this research, or any assistance with manuscript preparation. For the remaining authors there are no conflicts of interest.

\section{References}

1 Canena J: Once upon a time a guideline was used for the evaluation of suspected choledocholithiasis: a fairy tale or a nightmare? GE Port J Gastroenterol 2018;25:6-9.

2 Maydeo A, Kwek BEA, Bhandari S, Bapat M, Dhir V: Single-operator cholangioscopyguided laser lithotripsy in patients with difficult biliary and pancreatic ductal stones (with videos). Gastrointest Endosc 2011;74:13081314.

3 Patel S, Rosenkranz L, Hooks B, Tarnasky P, Raijman I, Fishman et al: Holmium-yttrium aluminum garnet laser lithotripsy in the treatment of biliary calculi using single-operator cholangioscopy: a multicenter experience (with video). Gastrointest Endosc 2014;79: 344-348.

4 Wong JC, Tang RS, Teoh AY, Sung JJ, Lau JY: Efficacy and safety of novel digital singleoperator peroral cholangioscopy-guided laser lithotripsy for complicated biliary stones. Endosc Int Open 2017;5:E54-E58.

5 Attwell AR, Patel S, Kahaleh M, Raijman IL, Yen R, Shah RJ: ERCP with per-oral pancreatoscopy-guided laser lithotripsy for calcific chronic pancreatitis: a multicenter US experience. Gastrointest Endosc 2015;82:311-318.

6 Leung JW, Chung SS: Electrohydraulic lithotripsy with peroral choledochoscopy. BMJ 1989;299:595-598.
7 Lux G, Ell C, Hochberger J, Müller, Demling $\mathrm{L}$ : The first successful endoscopic retrograde laser lithotripsy of common bile duct stones in man using a pulsed neodymium-YAG laser. Endoscopy 1986;18:144-145.

8 Das AK, Chiura DA, Conlin, Eschelman D, Bagley DH: Treatment of biliary calculi using holmium:yttrium aluminum garnet laser. Gastrointest Endosc 1998;48:207-209.

9 Chen YK, Pleskow DK: SpyGlass single-operator peroral cholangiopancreatoscopy system for the diagnosis and therapy of bile-duct disorders: a clinical feasibility study (with video). Gastrointest Endosc 2007;65:832-841.

10 Pereira P, Vilas-Boas F, Peixoto A, Andrade P, Lopes J, Macedo G: How SpyGlass ${ }^{\mathrm{TM}}$ may impact endoscopic retrograde cholangiopancreatography practice and patient management. GE Port J Gastroenterol 2018;25:132137.

11 Laleman W, Verraes K, Van Steenbergen W, Cassiman D, Nevens F, Van der Merwe S, et al: Usefulness of the single-operator cholangioscopy system SpyGlass in biliary disease: a single-center prospective cohort study and aggregated review. Surg Endosc 2017;31: 2223-2232.
12 Brewer Gutierrez OI, Bekkali NLH, Raijman I, Sturgess R, Sejpal DV, Aridi HD, et al: Efficacy and safety of digital single-operator cholangioscopy for difficult biliary stones. Clin Gastroenterol Hepatol 2017, Epub ahead of print.

13 Cotton PB, Lehman G, Vennes J, Geenen JE, Russell RC, Meyers WC, et al: Endoscopic sphincterotomy complications and their management: an attempt at consensus. Gastrointest Endosc 1991;37:383-393.

14 Navaneethan U, Hasan MK, Kommaraju K, Zhu X, Hebert-Magee S, Hawes RH, et al: Digital, single-operator cholangiopancreatoscopy in the diagnosis and management of pancreatobiliary disorders: a multicenter clinical experience (with video). Gastrointest Endosc 2016;84:649-655.

15 Buxbaum J, Sahakian A, Ko C, Jayaram P, Lane C, Yu CY, et al: Randomized trial of cholangioscopy-guided laser lithotripsy versus conventional therapy for large bile duct stones (with videos). Gastrointest Endosc 2018;87:1050-1060.

16 Sethi A, Chen YK, Austin GL, Brown WR, Brauer BC, Fukami NN, et al: ERCP with cholangiopancreatoscopy may be associated with higher rates of complications than ERCP alone: a single-center experience. Gastrointest Endosc 2011;73:251-256. 